\title{
General Psychiatry General Psychiatry Highlights
}

Jinghong Chen, ${ }^{01,2}$ Junxiu Zhao ${ }^{1}$

To cite: Chen J, Zhao J. General Psychiatry Highlights. General Psychiatry 2019;32:e100100. doi:10.1136/ gpsych-2019-100100

Received 05 June 2019 Accepted 18 June 2019
Check for updates

(C) Author(s) (or their employer(s)) 2019. Re-use permitted under CC BY-NC. No commercial re-use. See rights and permissions. Published by BMJ.

${ }^{1}$ General Psychiatry Editorial Office, Shanghai Mental Health Center, Shanghai, China

${ }^{2}$ Shanghai Key Laboratory of Psychotic Disorders, Shanghai Jiao Tong University School of Medicine, Shanghai, China

Correspondence to Dr Jinghong Chen; chenjh_008@hotmail.com
In issues 2 and 3 , some interesting and popular topics are presented and they may inspire new ideas in psychiatric research. A systematic review conducted by Dr Chen and her colleagues has drawn much attention to the worldwide media, that it was positive to treat anxiety symptoms by regulating intestinal flora (RIF).

To the knowledge of researchers, accurate measurement is very important in clinical evaluation and the means to make clinical measurement more objective has been pursued by researchers. Dr Yuan and colleagues proposed a new measurement method that attention bias may serve as a more objective measure for addictive severity, which is expected to replace subjective reporting in addiction research.

In the addiction field, it has attracted much attention that gaming disorder was first officially classified as a disease at the 72nd World Health Assembly on 25 May 2019. What is gaming disorder? How to diagnose it? How to treat and prevent gaming disorder? These questions are answered by the review about gaming disorder conducted by $\mathrm{Dr}$ $\mathrm{Liu}$ and colleagues. Moreover, Professor Zhao provides some practical comments on gaming disorder from the public health point of view. More details could be found through the following comments.

\section{HOW ABOUT REGULATING MICROBIOTA ON ANXIETY SYMPTOMS?}

On 20 May 2019, the Newsweek reported 'Eating the right food to boost gut bacteria could ease symptoms of anxiety' which highly praised the new systematic review published in General Psychiatry issue 2, 2019, about gut bacteria related with anxiety. ${ }^{1}$ Accumulating basic studies have indicated that gut microbiota (GM) can regulate brain function through the gut-brain axis, and dysbiosis of intestinal microbiota is closely related to anxiety. Clinical studies also indicated that in addition to the use of psychiatric drugs, we also should consider RIF to alleviate anxiety symptoms, especially for patients who are not suitable for the applications of psychiatric drugs. However, there is no specific evidence to support the efficacy of the treatment of anxiety symptoms by RIF.

Dr Chen and her colleagues conducted a systematic review of 3334 articles about the effects of regulating microbiota on anxiety symptoms and found that more than half of the studies included showed it was positive to treat anxiety symptoms by RIF. $^{2}$ There were two kinds of interventions (probiotic and non-probiotic interventions) to regulate intestinal microbiota, highlighted by that the non-probiotic (mainly prebiotics) interventions were more effective than the probiotic interventions. The probiotics and non-probiotics together might have a better effect on treating mood disorders like anxiety. Furthermore, the newly published studies on probiotics treating mental disorders tend to apply something else such as vitamin D or selenium in addition to using probiotic alone, which are consistent with the finding of this systematic review and suggest that mental disorders could be treated by regulating GM and the ways to RIF are diverse. Therefore, more basic studies and relevant clinical intervention studies should be carried out to explore the mechanism and relationship between the intestinal flora adjustment and improvement of anxiety.

\section{THE NEW CRAVING MEASUREMENT FOR ADDICTION PATIENTS}

The indicator of addiction severity in clinical studies, for a long time, relies on experienced craving report for drug-related cues. This condition ranges from both addictive assessments and diagnosis to the estimation of clinical intervention. However, self-report of craving is susceptible to the influences of social desirability and self-masking in many situations. This necessitates the development of an objective measurement that can detect one's real craving, which is independent of these obscuring factors.

The article by Dr Yuan's team entitled 'Assessing the severity of methamphetamine 
use disorder beyond the subjective craving report: the role of an attention bias test' shows that the attention bias test represents a more reliable indicator for the addictive severity in methamphetamine (MA) dependents. ${ }^{3}$ The authors observed that MA dependents, irrespective of high or low craving reports, showed similar attention bias to drug-related photographs by using correlation analyses. Moreover, attention bias instead of craving rating was significantly correlated with each of the three clinical indexes of addictive severity.

This study provides evidence that attention bias serves as a more objective measure for addictive severity compared with the traditional craving report in addiction research.

\section{THE VIEWS ABOUT GAMING DISORDER}

Gaming is an important form of entertainment and it can bring us a moment of pleasure. However, excessive gaming may cause serious consequences for players. Gaming disorder has become a significant issue in mental healthcare. Dr Liu and his team summarise the studies about gaming disorder and give us a detail introduction of the definition, epidemiology, aetiology, diagnosis, treatment and prevention of gaming disorder. ${ }^{4}$ Substantial evidence suggested that gaming disorder was an addiction-based mental disorder. In the review, the debates and future research directions on gaming disorder are also involved.

In this issue, Dr Zhao points out that the occurrence and development of gaming disorder are closely related to individual, psychological, family and social factors and they can affect individuals' physical, psychological, family and social functions. ${ }^{5}$ More importantly, the author concludes thatcomprehensive strategies including medical, psychological, family and social interventions could be adopted to prevent and reduce the harm of gaming disorder.

With the development of society, mental health has increasingly become an integrated part in people's lives; thus, it is an important work to explore more efficient methods for the diagnosis, treatment and prevention of mental illness through clinical practice and basic research. The forum in issue 2 was very popular which focused on the development of psychiatry in China in 10 years. In that forum, Dr Shi gave us a comprehensive understanding of psychiatry by describing the current development of psychiatry and comparing the changes of today's mental health with the past. ${ }^{6} \mathrm{He}$ also shared the possible scene of visiting a psychiatrist after 10 years. This forum brings us a new perspective to better understand the development of psychiatry.

Contributors JC wrote and proofread the article. JZ wrote the draft and prepared the materials.

Funding The authors have not declared a specific grant for this research from any funding agency in the public, commercial or not-for-profit sectors.

Competing interests None declared.

Patient consent for publication Not required.

Provenance and peer review Not commissioned; internally peer reviewed.

Open access This is an open access article distributed in accordance with the Creative Commons Attribution Non Commercial (CC BY-NC 4.0) license, which permits others to distribute, remix, adapt, build upon this work non-commercially, and license their derivative works on different terms, provided the original work is properly cited, appropriate credit is given, any changes made indicated, and the use is non-commercial. See: http://creativecommons.org/licenses/by-nc/4.0/.

\section{REFERENCES}

1. Kashmira Gander. Eating the right food to help reduce anxiety symptoms. Newsweek 2019.

2. Yang B, Wei J, Ju P, et al. Effects of regulating intestinal microbiota on anxiety symptoms: a systematic review. Gen Psychiatr 2019:32:59-67.

3. Liang Q, Yuan T, Cao X, et al. Assessing the severity of methamphetamine use disorder beyond the subjective craving report: the role of an attention bias test. Gen Psychiatr 2019;32:68-74.

4. Wang Q, Ren H, Liu TQ. Research progress and debates on gaming disorder. Gen Psychiatr 2019;32:99-104.

5. Zhao M, Hao W. Challenges of gaming disorder: suggestions from public health view. Gen Psychiatr 2019;32.

6. Shi S. What will the development of psychiatry in China be in 10 years? Gen Psychiatr 2019;32:92-4. 